\title{
Sustainability of poultry production using the emergy approach: Comparison of conventional and organic rearing systems
}

\author{
Cesare Castellini $^{\mathrm{a}, *}$, Simone Bastianoni ${ }^{\mathrm{b}}$, Claudio Granai ${ }^{\mathrm{b}}$, \\ Alessandro Dal Bosco ${ }^{\mathrm{a}}$, Mauro Brunetti ${ }^{\mathrm{c}}$ \\ ${ }^{a}$ Dip. Biologia Vegetale e Biotecnologie Agroambientali e Zootecniche, Università di Perugia, Borgo XX Giugno 74, 06121 Perugia, Italy \\ ${ }^{\mathrm{b}}$ Dip. Scienze e Tecnologie Chimiche e dei Biosistemi, Università di Siena, Italy \\ ${ }^{\mathrm{c}}$ Azienda agraria, Università di Perugia, Italy
}

Received 28 April 2005; received in revised form 26 October 2005; accepted 16 November 2005

Available online 18 January 2006

\begin{abstract}
The organic production system is an important strategy, compatible with sustainable agriculture, avoiding the use of chemical compounds, limiting the intensity of production and providing controls along the entire chain of production. The aim of this study is to compare conventional and organic poultry production in terms of emergy analysis. The main differences in the two systems were the emergy cost for poultry feed and for cleaning/sanitization of the buildings between successive productive cycles. In both production systems the poultry feed represented more than $50 \%$ of the emergy flow. Regarding the agronomic phase, it was shown that almost all the organic crops, avoiding chemical fertilizers and pesticides, saved around 60\% emergy. The emergetic costs for housing of the birds were very similar in both systems. Relating the emergy results with productive performance it is possible to show that, although the annual productive performance was much lower in organic than in conventional $(-206 \%)$, transformity of organic poultry was around $10 \%$ lower. Comparison of the organic poultry system with a conventional one from the viewpoint of sustainability showed that all the emergy-based indicators are in favour of the organic farming system with a higher efficiency in transforming the available inputs in the final product, a higher level of renewable inputs, a higher level of local inputs and a lower density of energy and matter flows.
\end{abstract}

(C) 2005 Elsevier B.V. All rights reserved.

Keywords: Poultry production; Organic farming system; Emergy

\section{Introduction}

The discrepancy between economic interests and safeguarding of the environment has created ecological problems throughout the world. About 20 years ago the United Nations proposed strategies for "sustainable development" to improve human well-being in the short term without threatening the environment in the long term (Brundtland Report-WCED, 1987). Such strategies are not simple to carried out and often economic interests interfere with them. Even in agriculture, farmers assess their productive practices mainly on economic efficiency, which

\footnotetext{
* Corresponding author. Tel.: +39 075 5857104; fax: +39 0755857122.

E-mail address: cesare@unipg.it (C. Castellini).
}

generally requires large amounts of inputs (both natural and technical) with scarce attention to environmental pollution (reduction of organic matter, concentration of toxic compounds, etc.) and to future reproducibility. According to the above-mentioned situation, the outlining of sustainable agriculture has become a major goal for research and public institutions.

The organic production system (Council Regulation, 1999) matches this aim, avoiding the use of synthetic chemical compounds, limiting the intensity of production and providing controls along the entire chain of production. Thus, the organic system improves local sustainability, whereas the effect on global sustainability is not easily assessable. Sustainability requires measurements that permit the suitability of the system to be assessed in short and long 
term and simultaneously the different systems to be compared.

Several methods that take into account a certain number of factors and indicators (soil erosion, $\mathrm{CO}_{2}$ emission, water pollution, etc.) are available for evaluating the environmental impact of agriculture (Hansen, 1996). Emergy evaluation (Odum, 1996) is a tool particularly suitable to this task because it deals at best with systems at the interface between the "natural" and the "human" spheres (Bastianoni and Marchettini, 1996) and because it is able to account for all the inputs on a common basis, avoiding difficulties and subjectivity that could take place with other methods (Life Cycle Assessment, Bakshi, 2002).

Traditional energy analysis provides the short-term feasibility of a process but it should be emphasized that all forms of energy do not have the same "quality". To measure such difference a method based on solar emergy (from now on simply emergy), defined as the solar (equivalent) energy required to generate that flow or storage, has been proposed. The units are solar emjoules (sej). The solar transformity is the emergy per unit flow or unit product and it has been proposed as a measure of the position of a given item in the thermodynamic hierarchy of the planet (Odum, 1988).

Human labour, information and technological devices have relatively small energy flows but high emergy flows are required for their formation and maintenance. These are energy flows of higher "quality" in the sense that they have a greater ability to feed back and amplify other flows. As a result, the expression of the energy value for different kinds of energy in joules is not accurate. Emergy analysis is also used to establish a long-term sustainability and to measure environmental stress. It considers a system with large boundaries, including all the inputs that contributed to the formation of a product, including the environmental ones that are taken as "free" in energy analysis (labour, etc.). Furthermore, the inputs are not considered only on the basis of their energy content, but are weighted by the transformities. In this way the emergy accounts for nature's "labour" necessary to obtain a given product. If an input has a high emergy content it means that it is likely to be a key factor in the production process; it needs a high effort to be re-established, and for this reason it may rise as a limiting factor, since it needs a large amount of space and/or time and/or energy.

While for other sectors/aspects, environmental sustainability using emergy evaluation is widely diffused (Lagerberg and Brown, 1999; Panzieri et al., 2000; Rydberg and Jansén, 2002; Zuo et al., 2004), information on the impact of different animal production systems are scarce. Hence, the aim of this paper is to compare conventional and organic poultry production system in terms of emergy analysis.

\section{Material and methods}

The main differences in these production systems regards the quantity and quality of inputs; further, the organic system had a direct re-use of manure (after 4 months of maturation) as fertilizer with no need for dehydration or sanitization.

\subsection{Crop production}

All the agronomical traits for both the conventional and organic systems were collected from the farm of the University of Perugia and are consistent with the farming systems adopted in Italy. Briefly, for each ingredient of the poultry diet, the amount produced and the major inputs (fuel, trucks, transport, irrigation, seeds, fertilizer, manpower, pesticides) were assessed.

\subsection{Poultry production}

The production traits and the performance were taken from the mean values of two poultry farms: conventional (Grighi, Todi, Italy) and organic (Perugia University, Italy) and are reported in Table 1. The genetic strains used for the conventional and organic system were Ross 205 and Kabir (Kabir chicks ltd., 1995), respectively. In conventional production, 1-day-old chicks were maintained in the same building for the entire length of the cycle; organic chicks were housed in a similar indoor pen $\left(0.12 \mathrm{~m}^{2} /\right.$ bird $)$, but with access to a grass paddock ( $\left.4 \mathrm{~m}^{2} / \mathrm{bird}\right)$ to assure for pasture allowance. At the end of each production cycle, after cleaning and sanitization, the buildings had an all in all out period of 2 weeks.

As recommended by organic regulations, the production techniques are developed in order to maximise animal welfare and the qualitative characteristics of the products (Castellini et al., 2003), e.g. to provide grass throughout the entire rearing period the birds were offered $10 \mathrm{~m}^{2} / \mathrm{bird}$ instead of $4 \mathrm{~m}^{2} /$ bird (required by Reg. 1804/99).

Energy and material requirements for poultry were assessed at the end of the growing period without considering transport to the slaughtering house, slaughtering, processing of carcasses and distribution.

The conventional diet was formulated with common ingredients (Table 2) according to the standard recommen-

Table 1

Main characteristics of the two farming systems

\begin{tabular}{|c|c|c|}
\hline & Conventional & Organic \\
\hline \multicolumn{3}{|l|}{ Buildings and space allowance } \\
\hline Birds per unit $(n)$ & 15600 & 1000 \\
\hline Surface area covered $\left(\mathrm{m}^{2}\right)$ & 988 & 96 \\
\hline Density (birds $/ \mathrm{m}^{2}$ covered surface) & 15.1 & 10.4 \\
\hline Pasture $\left(\mathrm{m}^{2} /\right.$ birds $)$ & - & 9.9 \\
\hline \multicolumn{3}{|l|}{ Productive performance $^{\mathrm{a}}$} \\
\hline Final weight $(\mathrm{g})$ & 2730 & 2210 \\
\hline Age at slaughtering (days) & 49 & 81 \\
\hline Daily weight gain (g/day) & 54.5 & 26.3 \\
\hline Units produced/year $(n)$ & 5.8 & 4.2 \\
\hline Feed index & 1.9 & 3.4 \\
\hline Mortality rate $(\%)$ & 4.5 & 9.9 \\
\hline
\end{tabular}

${ }^{a}$ Mean performance considering a female/male ratio $=1$. 
dations (Ross Breeders-Broiler management manual, 1999), whereas the organic ingredients were produced by the University farm and certified as organic by a national agency (ICEA). The main differences in organic feed formulation regarded the presence of fava-bean (13\%), the absence of GMO ingredients, of synthetic amino acids and coccidiostatics.

\subsection{Emergy evaluation}

The rules that describe emergy "algebra" are:

- all emergy sources of a process are assigned to the processes' output;

- by-products from a process have the total emergy assigned to each pathway;

- when a pathway splits, the emergy is assigned to each 'leg' of the split based on its percentage of the total energy flow on the pathway;

- emergy cannot be counted twice within a system: (a) emergy in feedbacks cannot be double counted; (b) byproducts, when reunited, cannot be added to equal a sum greater than the source emergy from which they were derived.

For an in-depth discussion of this issue and the differences between energy and emergy analyses, see Brown and Herendeen (1997). For our purpose it is important to note that in our calculations among solar energy, rain and wind only the highest of the three contributions to the total emergy flow will be considered, since they are co-products of the same phenomenon, i.e., the sunlight reaching the biosphere (Odum, 1996). Emergy analysis separates renewable from nonrenewable inputs and local from external inputs. These distinctions make it possible to define several emergy-based indicators that can provide decision support tools, especially when there are several alternatives (Bastianoni and Marchettini, 1996; Brown and McClanahan, 1996; Odum, 1996;

Table 2

Mean value of starter and finisher diets (\%) for the two farming systems

\begin{tabular}{lcc}
\hline & Conventional & Organic \\
\hline Maize (Zea mais) & 50.0 & 48.0 \\
Whole extruded soybean (Glycine max) & - & 16.0 \\
Barley (Hordeum vulgare) & - & 14.0 \\
Solvent-extracted soybean meal & 33.0 & - \\
Fava bean (Vicia faba var.) & - & 13.0 \\
Wheat-bran (Triticum vulgare) & 9.5 & - \\
Alfalfa meal (Medicago sativa) & 2.7 & 5.0 \\
Vitamin-mineral premix ${ }^{\mathrm{a}}$ & 1.0 & 1.0 \\
Vegetal oil & 2.0 & - \\
Dicalcium phosphate & 1.0 & 1.0 \\
Sodium bicarbonate & 0.5 & 0.5 \\
Salt & 0.2 & 0.2 \\
DL-methionine & 0.01 & - \\
L-lisine HCl & 0.01 & - \\
Coccidiostatic & 0.03 & - \\
\hline
\end{tabular}

${ }^{\mathrm{a}}$ Vitamins in the organic diet were provided by cod liver oil and malt yeast.
Ulgiati et al., 1995). These indicators (transformity, environmental loading ratio (ELR) and emergy yield ratio (EYR)) cover all the aspects of the environmental sustainability issues, even though not focused on a particular waste/ pollutant. When comparing two or more processes with the same output, a lower transformity is a measure of higher efficiency, i.e., more product obtained with a given quantity of emergy, or less emergy needed to produce a given amount of product. In particular, the values of the transformities are mostly taken from Odum (1996), with the important exception of the feed for the chicks; in this case, due to their relevance to the overall emergy, we performed an evaluation for each of the crops, obtaining transformity values that are tailored to this system.

EYR is the ratio of total emergy $(Y)$ to the emergy purchased on the market $(F)$, including fuel, goods and services. It is "a measure of the system's net contribution to the economy beyond its own operation" (Odum, 1996). Considering that the total emergy is the sum of all the local and external emergy inputs, the higher the ratio, the higher is the relative contribution of the local (renewable and nonrenewable) sources of emergy to the system. This index therefore shows how efficaciously the system uses the available local resources.

ELR is the ratio of all non-renewable emergy (both from inside and outside the system; $N+F$ ) to the renewable emergy $(R)$. This index is high for systems with a high technological level and/or with high environmental stress, which is not necessarily local, but is mostly located at the energy or materials source (Odum, 1996).

The renewable values were taken from the literature or directly calculated by the authors and are reported in Tables 3 and 4.

Emergy flow (or empower) density is the ratio of the total emergy per unit time and unit area and represents the spatial concentration of emergy (i.e. energy and material of different kinds), very often correlated with a high level of local environmental stress.

\section{Results}

\subsection{Poultry production performance}

The productive performances of the two farming systems showed large differences for the final weight, age at slaughtering, feed index and mortality rate (Table 1).

In conventional system, the use of fast-growing genotypes reared in well-controlled environments with the aid of veterinary treatments (coccidiostatics and antibiotics) permitted to obtain heavier animals in only 49 days. On the contrary, the organic chicks have to remain in the farm for at least 81 days without the use of any prophylactic or therapeutic drugs.

This is the main reason for explaining the higher feed index and mortality rate of the organic birds. 
Table 3

Emergy evaluation of conventional chicken production

\begin{tabular}{|c|c|c|c|c|c|c|}
\hline & Input & Unit & $\begin{array}{l}\text { quantity/ } \\
\text { cycle }\end{array}$ & $\begin{array}{l}\text { Solar transformity } \\
\text { (sej/U) }\end{array}$ & $\begin{array}{l}\text { Emergy flow } \\
\left(10^{14} \text { sej }\right) / \text { cycle }\end{array}$ & Type of input \\
\hline 1 & Solar energy & $\mathrm{J}$ & $5.98 \times 10^{12}$ & 1 & 0.06 & $R$ \\
\hline 2 & Rain & $\mathrm{g}$ & $1.05 \times 10^{9}$ & $8.99 \times 10^{4}$ & 0.94 & $R$ \\
\hline 3 & Wind & $\mathrm{J}$ & $1.36 \times 10^{10}$ & $1.50 \times 10^{3}$ & 0.20 & $R$ \\
\hline 4 & Geothermic heat & $\mathrm{J}$ & $4.85 \times 10^{9}$ & $2.55 \times 10^{4}$ & 1.24 & $R$ \\
\hline 5 & Soil erosion & $\mathrm{J}$ & $3.48 \times 10^{8}$ & $7.38 \times 10^{4}$ & 0.26 & $N$ \\
\hline 6 & Maize irrigated & $\mathrm{g}$ & $1.72 \times 10^{7}$ & $1.40 \times 10^{9}$ & 241.11 & $22 \% R 78 \% F$ \\
\hline 7 & Wheat bran & $\mathrm{g}$ & $2.65 \times 10^{6}$ & $3.02 \times 10^{9}$ & 80.05 & $42 \% R 58 \% F$ \\
\hline 8 & Alfa-alfa hay & $\mathrm{g}$ & $5.53 \times 10^{5}$ & $3.03 \times 10^{8}$ & 1.68 & $64 \% R 36 \% F$ \\
\hline 9 & Soybean oil solvent-extracted & $\mathrm{J}$ & $1.25 \times 10^{10}$ & $1.66 \times 10^{5}$ & 20.71 & $10 \% R 90 \% F$ \\
\hline 10 & Soybean meal & $\mathrm{g}$ & $1.13 \times 10^{7}$ & $1.82 \times 10^{9}$ & 204.95 & $10 \% R 90 \% F$ \\
\hline 11 & Salt & $\mathrm{g}$ & $6.62 \times 10^{4}$ & $1.00 \times 10^{9}$ & 0.66 & $F$ \\
\hline 12 & Bicalcium phosphate & $\mathrm{g}$ & $3.31 \times 10^{5}$ & $3.90 \times 10^{9}$ & 12.92 & $F$ \\
\hline 13 & Calcium bicarbonate & $\mathrm{g}$ & $3.31 \times 10^{5}$ & $1.00 \times 10^{9}$ & 3.31 & $F$ \\
\hline 14 & Additives & $\mathrm{g}$ & $2.65 \times 10^{5}$ & $1.48 \times 10^{10}$ & 39.21 & $F$ \\
\hline 15 & DL-methionine & $\mathrm{g}$ & $3.31 \times 10^{3}$ & $1.48 \times 10^{10}$ & 0.49 & $F$ \\
\hline 16 & Coccidiostatic & $\mathrm{g}$ & $1.09 \times 10^{4}$ & $1.48 \times 10^{10}$ & 1.62 & $F$ \\
\hline 17 & Plastics & $\mathrm{g}$ & $1.16 \times 10^{3}$ & $5.87 \times 10^{9}$ & 0.07 & $F$ \\
\hline 18 & Buildings & $\mathrm{g}$ & $6.00 \times 10^{2}$ & $7.48 \times 10^{8}$ & 0.00 & $F$ \\
\hline 19 & Human labour & $\mathrm{J}$ & $6.78 \times 10^{8}$ & $7.38 \times 10^{6}$ & 50.01 & $5 \% R 95 \% F$ \\
\hline 20 & Fuel & $\mathrm{J}$ & $4.60 \times 10^{8}$ & $6.60 \times 10^{4}$ & 0.30 & $F$ \\
\hline 21 & Feeders and drinkers & $\mathrm{g}$ & $8.75 \times 10^{3}$ & $2.64 \times 10^{9}$ & 0.23 & $F$ \\
\hline 22 & Drugs (antibiotics) & $\mathrm{g}$ & $5.50 \times 10^{3}$ & $1.48 \times 10^{10}$ & 0.81 & $F$ \\
\hline 23 & Sanitization & $\mathrm{g}$ & $3.84 \times 10^{5}$ & $1.48 \times 10^{10}$ & 56.86 & $F$ \\
\hline 24 & Wheat straw for litter & $\mathrm{J}$ & $4.94 \times 10^{10}$ & $4.30 \times 10^{3}$ & 2.13 & $42 \% R 58 \% F$ \\
\hline 25 & Potable water & $\mathrm{g}$ & $9.60 \times 10^{6}$ & $4.74 \times 10^{7}$ & 4.55 & $N$ \\
\hline$(R)$ & Renewable inputs (sum of items $2,4,6,7,8,9,10,19,24$ ) & & & & 115.88 & \\
\hline$(N)$ & Local non-renewable inputs (sum of 5 and 25) & & & & 4.81 & \\
\hline$(F)$ & Imported non-renewable inputs (the remainder) & & & & 603.43 & \\
\hline$(Y)$ & Total emergy flow & & & & 724.12 & \\
\hline
\end{tabular}

$R=$ renewable emergy; $N=$ local non-renewable emergy; $F=$ imported emergy.

\subsection{Emergy evaluation}

Results of emergy evaluations of conventional and organic poultry production are presented in Tables 3 and 4 , respectively. These tables are composed of:

- column 1: list of the inputs;

- column 2: the unit for each input/cycle (grams or Joules);

- column 3: the solar transformity of each input (sej/g or sej/J);

- column 4: the contribution of each input to the total emergy $\left(10^{14}\right.$ sej/cycle);

- column 5: the type of input (renewable, local nonrenewable, imported).

The main differences in the two systems were the emergy cost for poultry feed, for veterinary drugs and for cleaning/ sanitization of the buildings between successive productive cycles. According to the organic regulations, the molecules available for sanitization are only few and have low environmental impact (see annex 2 of Reg. 1804/99).

On the contrary, the emergy for the bird housing was very similar in both systems. Although production the environment was poor in organic and the absolute value was very low, the higher animal density and number of cycles per year in the conventional system reduced the energetic cost per $\mathrm{kg}$ meat produced.

Such differences in emergy values depend on variations in raw data (column 2) and on their transformity: the first are mainly affected by intensity of production (number of chickens, length of the cycle) whereas the latter are affected by system of production (use of certain production factors and emergy needs for such factors).

In both of the production systems the poultry feed represented more than $50 \%$ of the emergy flow. However, the different raw ingredients used and the emergy necessary for producing such ingredients affected the emergy values of the two diets differently. In conventional diets the synthetic amino acids and vitamins, the solvent-extracted soybean and the coccidiostatic - which cannot be used in organic production - were the most important outflows of the total emergy expenditure.

Concurrently, the system of crop cultivation affected the transformities: for example maize was not irrigated in the organic farm, while it was irrigated in the conventional one.

Since, the diet was the most important factor in the whole emergy evaluation, a detailed table of the agricultural inputs of non-irrigated maize are shown (Table 5). The transformed/emergy per unit mass resulting from this evaluation $\left(8.88 \times 10^{8} \mathrm{sej} / \mathrm{g}\right)$ was then used in Table 4 (item 6$)$, also 
Table 4

Emergy evaluation of organic chicken production

\begin{tabular}{|c|c|c|c|c|c|c|}
\hline & Input & Unit & $\begin{array}{l}\text { Quantity/ } \\
\text { cycle }\end{array}$ & $\begin{array}{l}\text { Solar transformity } \\
(\text { sej/U) }\end{array}$ & $\begin{array}{l}\text { Emergy flow } \\
\left(10^{14} \text { sej }\right) / \text { cycle }\end{array}$ & Type of input \\
\hline 1 & Solar energy & $\mathrm{J}$ & $9.72 \times 10^{12}$ & 1 & 0.10 & $R$ \\
\hline 2 & Rain & $\mathrm{g}$ & $1.71 \times 10^{9}$ & $8.99 \times 10^{4}$ & 1.53 & $R$ \\
\hline 3 & Wind & $\mathrm{J}$ & $2.21 \times 10^{10}$ & $1.50 \times 10^{3}$ & 0.33 & $R$ \\
\hline 4 & Geothermic heat & $\mathrm{J}$ & $5.52 \times 10^{9}$ & $2.55 \times 10^{4}$ & 1.41 & $R$ \\
\hline 5 & Soil erosion & $\mathrm{J}$ & $5.65 \times 10^{8}$ & $7.38 \times 10^{4}$ & 0.42 & $N$ \\
\hline 6 & Maize not-irrigated $^{\mathrm{a}}$ & $\mathrm{g}$ & $3.13 \times 10^{6}$ & $8.88 \times 10^{8}$ & 27.78 & $58 \% R 42 \% F$ \\
\hline 7 & Fava-bean & $\mathrm{g}$ & $1.41 \times 10^{6}$ & $4.38 \times 10^{8}$ & 6.17 & $80 \% R 20 \% F$ \\
\hline 8 & Alfa-alfa hay & $\mathrm{g}$ & $2.35 \times 10^{5}$ & $3.97 \times 10^{8}$ & 0.93 & $82 \% R 18 \% F$ \\
\hline 9 & Barley & $\mathrm{g}$ & $1.64 \times 10^{6}$ & $4.21 \times 10^{8}$ & 6.92 & $45 \% R 55 \% F$ \\
\hline 10 & Soybean & $\mathrm{g}$ & $1.17 \times 10^{6}$ & $1.82 \times 10^{9}$ & 21.35 & $10 \% R 90 \% F$ \\
\hline 11 & Salt & $\mathrm{g}$ & $3.91 \times 10^{4}$ & $1.00 \times 10^{9}$ & 0.39 & $F$ \\
\hline 12 & Dicalcium phosphate & $\mathrm{g}$ & $7.82 \times 10^{4}$ & $3.90 \times 10^{9}$ & 3.05 & $F$ \\
\hline 13 & Calcium carbonate & $\mathrm{g}$ & $3.91 \times 10^{4}$ & $1.00 \times 10^{9}$ & 0.39 & $F$ \\
\hline 14 & Mineral-vitamin premix & $\mathrm{g}$ & $7.82 \times 10^{4}$ & $1.48 \times 10^{10}$ & 11.57 & $F$ \\
\hline 15 & Wood & $\mathrm{g}$ & $7.50 \times 10^{3}$ & $4.04 \times 10^{8}$ & 0.03 & $R$ \\
\hline 16 & Fence & $\mathrm{g}$ & $1.95 \times 10^{4}$ & $2.64 \times 10^{9}$ & 0.51 & $F$ \\
\hline 17 & Plastic & $\mathrm{g}$ & $1.16 \times 10^{3}$ & $3.80 \times 10^{8}$ & 0.00 & $F$ \\
\hline 18 & Buildings and shelter & $\mathrm{g}$ & $6.00 \times 10^{2}$ & $2.64 \times 10^{9}$ & 0.02 & $F$ \\
\hline 19 & Human Labour & $\mathrm{J}$ & $1.20 \times 10^{8}$ & $7.38 \times 10^{6}$ & 8.88 & $5 \% R 95 \% F$ \\
\hline 20 & Fuel & $\mathrm{J}$ & $4.60 \times 10^{8}$ & $6.60 \times 10^{4}$ & 0.30 & $F$ \\
\hline 21 & Feeders and drinkers & $\mathrm{g}$ & $8.75 \times 10^{2}$ & $2.64 \times 10^{9}$ & 0.02 & $F$ \\
\hline 22 & Veterinary treatments & $\mathrm{g}$ & $1.10 \times 10^{3}$ & $1.48 \times 10^{10}$ & 0.16 & $F$ \\
\hline 23 & Disinfectants & $\mathrm{g}$ & $2.00 \times 10^{4}$ & $1.00 \times 10^{9}$ & 0.20 & $F$ \\
\hline 24 & Wheat straw for litter & $\mathrm{j}$ & $6.87 \times 10^{9}$ & $4.30 \times 10^{3}$ & 0.30 & $42 \% R 58 \% F$ \\
\hline 25 & Agricultural Water & $\mathrm{g}$ & $9.48 \times 10^{6}$ & $1.26 \times 10^{6}$ & 0.12 & $N$ \\
\hline$(R)$ & Renewable inputs (sum of items $2,4,6,7,8,9,10,19,24$ ) & & & & 26.58 & \\
\hline$(N)$ & Local non-renewable inputs (sum of 5 and 25) & & & & 0.54 & \\
\hline$(F)$ & Imported non-renewable inputs (the remainder) & & & & 65.04 & \\
\hline$(Y)$ & Total emergy flow & & & & 92.16 & \\
\hline
\end{tabular}

$R=$ renewable emergy; $N=$ local non-renewable emergy; $F=$ imported emergy.

${ }^{a}$ Emergy evaluation of organic maize is reported in Table 5.

Table 5

Emergy evaluation of organic maize production

\begin{tabular}{|c|c|c|c|c|c|c|}
\hline & Input & Unit & $\begin{array}{l}\text { Quantity/ } \\
\text { cycle }\end{array}$ & $\begin{array}{l}\text { Solar transformity } \\
(\mathrm{sej} / \mathrm{U})\end{array}$ & $\begin{array}{l}\text { Emergy flow } \\
\left(10^{14} \text { sej }\right) / \text { cycle }\end{array}$ & Type of input \\
\hline 1 & Solar energy & $\mathrm{J}$ & $9.72 \times 10^{12}$ & 1 & 0.39 & $R$ \\
\hline 2 & Rain & $\mathrm{g}$ & $1.71 \times 10^{9}$ & $8.99 \times 10^{4}$ & 7.34 & $R$ \\
\hline 3 & Wind & $\mathrm{J}$ & $2.21 \times 10^{10}$ & $1.50 \times 10^{3}$ & 1.32 & $R$ \\
\hline 4 & Geothermic heat & $\mathrm{J}$ & $5.52 \times 10^{9}$ & $2.55 \times 10^{4}$ & 5.63 & $R$ \\
\hline 5 & Soil erosion & $\mathrm{J}$ & $5.65 \times 10^{8}$ & $7.38 \times 10^{4}$ & 0.01 & $N$ \\
\hline 6 & Poultry manure ${ }^{a}$ & $\mathrm{~g}$ & $2.20 \times 10^{6}$ & $2.96 \times 10^{9}$ & 0.00 & \\
\hline 7 & Seeds & $\mathrm{g}$ & $4.00 \times 10^{4}$ & $8.87 \times 10^{8}$ & 0.35 & $R$ \\
\hline 8 & Fuel & $\mathrm{J}$ & $7.17 \times 10^{9}$ & $6.56 \times 10^{4}$ & 4.71 & $F$ \\
\hline 9 & Human labour & $\mathrm{J}$ & $6.28 \times 10^{6}$ & $7.38 \times 10^{6}$ & 0.46 & $F$ \\
\hline 10 & Machinery & $\mathrm{g}$ & $1.02 \times 10^{3}$ & $6.70 \times 10^{9}$ & 0.07 & $F$ \\
\hline 11 & Cow manure & $\mathrm{g}$ & $1.50 \times 10^{7}$ & $1.13 \times 10^{8}$ & 16.95 & $30 \% R 70 \% F$ \\
\hline$(R)$ & Renewable inputs (sum of items $2,4,7$ ) & & & & 20.47 & \\
\hline$(N)$ & Local non-renewable inputs (5) & & & & 0.01 & \\
\hline$(F)$ & Imported non-renewable inputs (sum of items $8,9,10$ ) & & & & 15.04 & \\
\hline \multirow[t]{2}{*}{$(Y)$} & Total emergy flow & $\mathrm{g}$ & $4.00 \times 10^{6}$ & $8.88 \times 10^{8}$ & 35.52 & \\
\hline & & $\mathrm{J}$ & $5.94 \times 10^{9}$ & $5.98 \times 10^{5}$ & & \\
\hline
\end{tabular}

$R=$ renewable emergy; $N=$ local non-renewable emergy; $F=$ imported emergy.

${ }^{a}$ Poultry manure has emergy equal to zero because it is recycled within the system (4th rule of the emergy algebra); cow manure comes from another system and therefore considered. 
considering the characteristics of renewability/non-renewability emerging from the relations between $R, N$ and $F$ with the total emergy flow. The same procedure was followed for all the agricultural ingredients of the chicken diet.

In this respect, it has been shown that almost all the organic crops, which do not use chemical fertilizers and pesticides, saved around 60\% emergy. See for example the ratio of the transformities of maize: organic/conventional $=58 \%$; Alfalfa hay: organic/conventional $=65 \%$.

It is important to note that soil was assumed to be a local non-renewable resource. This is due to the fact that soil could be considered as a storage that is used up during the agricultural production and then replenished only if proper farming procedures are performed. However, considering that generally the speed of consumption is higher than the natural reformation, this input has been considered nonrenewable. Otherwise the input is very small and the error in the global evaluation is negligible.

\subsection{Emergy-based indicators}

The impressive difference in the amount of emergy should not be considered by itself; however, the emergy flow of a conventional cycle was around eight times greater than the organic one, while the farmland used is much less in the former than in the latter. This is reflected in a very relevant difference in the empower density (Table 6). Considering that in 1 year there are 4.2 cycles of organic chicks and 5.8 cycles of the conventional ones, the amount of emergy concentrated in a unit area is 198 times larger in the conventional case.

Relating the emergy results with productive performance, it is possible to show that, although the annual productive performance was much lower in organic than in conventional $(-206 \%)$, transformity of organic poultry was around $10 \%$ lower. The difference in efficiency is not relevant, even if the error was minimised using local transformities for the main inputs. It should be emphasized that emergy efficiency can be compared only for homogeneous products, however, the qualitative characteristics of the two chicken meats are different; in fact the sensory and nutritional characteristics of the organic meat are better (Castellini et al., 2002a,b).

Table 6 also shows that the other indexes are consistent in indicating the organic system as the one with better environmental performance: EYR is higher, indicating a

Table 6

Emergy-based indicators of conventional and organic chicken production

\begin{tabular}{lll}
\hline Emergy-based indicator & Conventional & Organic \\
\hline Solar transformity (sej/J) & $6.11 \times 10^{5}$ & $5.79 \times 10^{5}$ \\
Solar transformity (sej/g) & $4.35 \times 10^{9}$ & $4.12 \times 10^{9}$ \\
Emergy yield ratio (EYR) & 1.19 & 1.51 \\
Environmental loading ratio (ELR) & 5.21 & 2.04 \\
${\text { Empower density }{ }^{\mathrm{a}} \text { (sej/year)/m }}^{2}$ & $7.80 \times 10^{14}$ & $3.69 \times 10^{12}$ \\
\hline
\end{tabular}

${ }^{\mathrm{a}}$ Empower density was calculated on a yearly basis, since cycles are of different length. relatively less relevant use of external inputs, that is a higher level of dependence on local ones; ELR, on the other hand, shows that the non-renewable part of the emergy is 5.25 and 2.04 times higher than the renewable part for conventional and organic production, respectively, meaning that the imbalance in favour of the non-renewable is less than half for the organic with respect to the conventional type.

\section{Discussion}

It should be pointed out that while the emergy values of the conventional poultry production must be considered characteristic of the farming system most commonly used in Italy, those of the organic system are more related to the case-study shown here. Until now, the organic poultry system has not had a standardized production protocol and often protocols tailored for intensive systems (diets, environments and genetic strains) are adapted without any modifications. In this context one of the most critical factors is the genetic strain of the chicks. Reg. 1804/99 recommends using slow-growing animals, but economic reasons give incentive to using fast-growing birds, even if they are not adapted to the organic system. Such animals have been intensively selected for growth rate and feed conversion (Thiele, 2001) and behave very differently from some of the less intensively selected strains (Network For Animal Health And Welfare In Organic Agriculture, 2002). Selection has reduced all the activities involving high energetic costs, making it possible for the birds to reallocate the energy saved to production traits. Modern meat-type birds, when kept to older ages, gain excessive weight and have leg weakness, make little use of pasture and tend to stay indoors or near the house rather than forage in the pasture (Weeks et al., 1994). Indirectly, the density of animals in the same area creates problems of excessive nitrogen and phosphorus concentration (Kratz et al., 2004b).

On the contrary, slow-growing genotypes have greater locomotive activity and pasture aptitude and greater resistance to the poorer conditions of the organic farming system than the modern faster growing hybrids (Vaarst et al., 2004).

Only specific farming models are able to maximize all the potential benefits of organic farming. This farming model should search for a suitable interaction between all the factors, considering not only the productivity and economic indexes. In this way - with production protocols similar to those analysed here, is possible to achieve other advantages, not considered in this research, which regard the welfare condition of the animals (Castellini et al., 2003; Weeks et al., 1994) and the meat characteristics (Castellini et al., 2002a,b).

Comparison with other research is difficult because different aspects of the environmental impact were analysed; however, our results are consistent with the main findings. Some authors, comparing the environmental impact by LCA of intensive, extensive and organic dairy farms, showed that 
organic farms had clear advantages in term of energy consumption, animal husbandry, and biodiversity and landscape image. These indices largely depend on the modulation of the systems. In particular, intensive farms consume a significantly higher amount of fossil energy due to the use of industrial grass drying plants and mineral $\mathrm{N}$-fertilizer. Compared with the intensive conventional farms in Germany, organic farms need around 65\% less energy (Haas et al., 2001).

Kratz et al. (2004a), evaluating the nitrogen, phosphorus, zinc and copper balance (intake-retained) of different poultry production systems (intensive indoor, free range and organic), showed that the nutrient efficiency of indoor production was higher than in free range and organic. The main reasons for these differences were related to the longer growing period, the broiler strain and the feeding strategy. Nevertheless, the whole farm indicators (livestock density, $\mathrm{N}$ and $\mathrm{P}$ excretions per hectare) demonstrate that organic farms had the lowest livestock densities and the lowest $\mathrm{N}$ and $\mathrm{P}$ excretions per hectare.

Kumm (2002) suggested that the sustainability of organic production could also depend on the species considered: positive for beef and lamb and not for pork. Organic pork production showed that the production costs and the discharge of nitrogen and greenhouse gases per $\mathrm{kg}$ of meat are higher than in conventional pork production due to the greater feed efficiency of conventional pork production. Organic production also needs more land, which limits its sustainability if land for food production and energy crops is scarce.

It should be considered that organic production at least in Italy must be performed in marginal areas, often neglected by farmers (Zanoli, 1999).

Naturally, even for organic poultry meat, the cost of production is much higher than in conventional rearing. However, at a time when the limiting factor for development is more, the availability of resources and the environmental problems connected to a constant tendency towards economic growth, it may be important to give less relevance to this factor.

A more holistic evaluation of agricultural systems should determine a policy of incentives towards those productive systems, which are able to improve environmental sustainability, the quality of food for humans and animal welfare. In addition, further indicators of sustainability such as human and ecological toxicity in term of residues (heavy metals, antibiotics) should be considered. Campagnolo et al. (2002) have shown that a wide spectra of antimicrobial residues are present in waste and water resources proximal to poultry and swine farms. Even for this aspect, the organic farming system has an important card to play.

\section{Conclusion}

The comparison of an experimental organic poultry farm with a conventional one from the viewpoint of sustainability showed that all the emergy-based indicators are in favour of the organic farming system. In particular there is:

higher efficiency in transforming the available inputs in final product;

higher level of renewable inputs;

higher level of local inputs;

lower density of energy and matter flows.

Clearly, to maximise environmental sustainability, food safety and biodiversity, specific farming protocols should be developed. Furthermore organic farming requires additional research.

\section{Acknowledgements}

Research funded by Progetto Interregionale Sviluppo Rurale, sottoprogetto Zootecnia Biologica-Legge 499/99. The authors wish to thank Giovanni Migni and Dino Parasecoli for technical assistance.

\section{References}

Bakshi, B., 2002. A thermodynamic framework for ecologically conscious process systems engineering. Comput. Chem. Eng. 26, 269-282.

Bastianoni, S., Marchettini, N., 1996. Ethanol production from biomass: analysis of process efficiency and sustainability. Biomass Bioeng. 11, 411-418.

Brown, M.T., McClanahan, T., 1996. Emergy analysis perspectives of Thailand and Mekong river dam proposals. Ecol. Model. 91, 105-130.

Brown, M.T., Herendeen, R.A., 1997. Embodied energy analysis and EMERGY analysis: a comparative view. Ecol. Econ. 19, 219-235.

Bruntland, G. (Ed.), 1987. Our Common Future: The World Commission on Environment and Development. Oxford University Press, Oxford.

Campagnolo, E.R., Johnson, K.R., Karpati, A., Rubin, C.S., Kolpin, D.W., Meyer, M.T., Esteban, J.E., Currier, R.W., Smith, K., Thu, K.M., McGeehin, M., 2002. Antimicrobial residues in animal waste and water resources proximal to large-scale swine and poultry feeding operations. Sci. Total Environ. 299, 89-95.

Castellini, C., Mugnai, C., Dal Bosco, A., 2002a. Effect of conventional versus organic method of production on the broiler carcass and meat quality. Meat Sci. 60, 219-225.

Castellini, C., Mugnai, C., Dal Bosco, A., 2002b. Meat quality of three chicken genotypes reared according to the organic system. Ital. J. Food Sci. 4, 401-412.

Castellini, C., Dal Bosco, A., Mugnai, C., Bernardini, M., 2003. Performance and behaviour of chickens with different growing rate reared according to the organic system. Ital. J. Anim. Sci. 6, 561-573.

Council Regulation (EC) No. 1804/99 of July 1999 supplementing Regulation (EEC) No. 2092/91 on organic production of agricultural products. Off. J., L 222, 24/08/1999, pp. 1-28.

Haas, G., Wetterich, F., Köpke, U., 2001. Comparing intensive, extensified and organic grassland farming in southern Germany by process life cycle assessment. Agric. Ecosyst. Environ. 873, 43-53.

Hansen, J.W., 1996. Is agricultural sustainability a useful concept? Agric. Syst. 50, 117-143.

Kabir chicks Ltd., Katz, Z., 1995. Breeders have to take nature into account. World Poultry Sci. 11, 124-133, http://www.kabir.co.il/.

Kratz, S., Halle, I., Rogasik, J., Schnug, E., 2004a. Nutrient balance indicators for sustainability of broiler production systems. Brit. Poultry Sci. 2, 149-157. 
Kratz, S., Rogasik, J., Schnug, E., 2004b. Changes in soil nitrogen and phosphorus under different broiler production systems. J. Environ. Qual. 33, 1662-1674.

Kumm, K., 2002. Sustainability of organic meat production under Swedish conditions. Agric. Ecosyst. Environ. 88, 95-101.

Lagerberg, C., Brown, M.T., 1999. Improving agricultural sustainability: the case of Swedish greenhouse tomatoes. J. Cleaner Prod. 7, 421434.

National Research Council, 1994. Nutrient Requirement of Poultry. National Academy Press, Washington, DC.

Network For Animal Health And Welfare In Organic Agriculture, 2002. Final recommendation and comments, http://www.veeru.reading.ac.uk/ organic/.

Odum, H.T., 1988. Self-organization, transformity, and information. Science 242, 1132-1139.

Odum, H.T., 1996. Environmental accounting: Emergy and Environmental Decision Making. Wyley \& Sons, New York, USA, p. 370.

Panzieri, M., Marchettini, N., Hallam, T.G., 2000. Importance of the Bradhyrzobium japonicum symbiosis for the sustainability of soybean cultivation. Ecol. Model. 135, 301-310.

Ross Breeders, 1999. Broiler Management Manual. Ross Breeders Ltd., Newbridge, Midlothian, UK.

Rydberg, T., Jansén, J., 2002. Comparison of horse and tractor traction using emergy analysis. Ecol. Eng. 19, 13-28.
Thiele, H.H., 2001. Breeding strategies to increase fitness in poultry. Dtsch Tierarztl Wochenschr 108, 140-148.

Ulgiati, S., Brown, M.T., Bastianoni, S., Marchettini, N., 1995. Emergybased indices and ratios to evaluate the sustainable use of resources. Ecol. Eng. 5, 519-531.

Vaarst, M., Rodericj, S., Lund, V., Lockeretz, W., 2004. Animal Health and Welfare in Organic Agriculture. CABI ed., Wallingford, UK.

Weeks, C.A., Nicol, C.J., Sherwin, C.M., Kestin, S.C., 1994. Comparison of the behaviour of broiler chicken in indoor and free-range environments. Anim. Welfare 3, 179-192.

Zanoli, R., 1999. Economic performance and potential of organic farming. In: Proceedings of the Organic Farming in the European Union-Perspectives for the 21st Century, Baden, Austria.

Zuo, P., Wan, S.W., Qin, P., Du, J., Wang, H., 2004. A comparison of the sustainability of original and constructed wetlands in Yancheng Biosphere Reserve China: implications from emergy evaluation. Environ. Sci. Pol. 11, 329-343.

\section{Further reading}

Daly, H.E., 1989. Building Sustainable Societies. Cobb Beacon Press, Oxford. 